\title{
Use of high flow nasal cannula for preoxygenation and apneic oxygenation during intubation
}

\author{
Jean-Damien Ricard ${ }^{1,2}$, Baptiste Gaborieau ${ }^{1,2}$, Juliette Bernier $^{1}$, Camille Le Breton ${ }^{1}$, Jonathan Messika ${ }^{3}$ \\ ${ }^{1}$ Intensive Care Unit, Louis-Mourier Hospital, Colombes, France; ${ }^{2}$ University of Paris, Paris, France; ${ }^{3}$ University of Paris, Physiopathology and \\ Epidemiology of Respiratory Diseases, Paris, France \\ Correspondence to: Prof. Jean-Damien Ricard, MD, PhD. Medical-Surgical Intensive Care Unit, Louis-Mourier Hospital, F-92700, Colombes, France. \\ Email: jean-damien.ricard@aphp.fr. \\ Provenance: This is an invited article commissioned by the Guest Section Editor Biao Zhang (Department of Critical Care Medicine, Suzhou \\ Integrated Chinese and Western Medicine Hospital, Suzhou, China). \\ Comment on: Guitton C, Ehrmann S, Volteau C, et al. Nasal high-flow preoxygenation for endotracheal intubation in the critically ill patient: a \\ randomized clinical trial. Intensive Care Med 2019;45:447-58.
}

Submitted Dec 06, 2018. Accepted for publication Dec 16, 2019.

doi: 10.21037/atm.2019.12.106

View this article at: http://dx.doi.org/10.21037/atm.2019.12.106

Need for intubation in patients with acute respiratory failure remains important when respiratory condition deteriorates and places these severely hypoxemic patients at higher risks of desaturation than patients without respiratory failure (1). Between 30 to $40 \%$ of patients with acute respiratory failure will require intubation despite initial management with high flow nasal cannula (HFNC) oxygen (2-4).

This figure is higher in patients initially treated with non-invasive ventilation or with standard conventional oxygen, in particular in those with a $\mathrm{PaO}_{2} / \mathrm{FIO}_{2}$ below $200(4,5)$. These patients are obviously at high risk of desaturation during the procedure.

\section{Timing and decision of intubation}

In addition to initial level of hypoxemia, timing of intubation is a key feature to consider when discussing hazards of intubation and how to avoid them (6). Interestingly, data in the literature suggests that optimal timing may differ depending on the patient's primary diagnosis. In the case of acute hypoxemic respiratory failure, studies have found that unduly delaying intubation worsens patients' outcome (7). Conversely, in septic shock, a post-hoc analysis of the Sepsispam study found that practices regarding intubation affected patient outcome (8). Those ICUs with the highest rate of early intubation had a greater proportion of mortality in comparison to ICUs with middle rate of early intubation. Those ICUs with the lowest rate of early intubation had a non-significant increased mortality. Because intubation of septic patients may be prompted by either hemodynamic, respiratory or neurologic reasons, and because sepsis often originates from pneumonia, it is difficult to draw any firm conclusion from this post-hoc analysis, but taken together, data clearly indicates that late is not desirable, but early may also be associated with worse outcome. Hence, appropriate timing of intubation during high flow therapy is a daily challenge. Predicting which patients will fail and require intubation is hazardous and determining optimal time to intubate not always easy. Recently, we developed an index to help predict outcome of patients receiving HFNC. The ROX index (which is defined by the ratio of $\mathrm{SpO}_{2}$ over $\mathrm{FiO}_{2}$, divided by respiratory rate) has its best accuracy to identify which patients will succeed and which will fail under HFNC when it is calculated at $12 \mathrm{~h}$ after the start of HFNC therapy $(2,3)$. Importantly, the dynamics of changes of the ROX are also discriminative, hence the index can be calculated over time, and an increasing ROX is associated with a better outcome than a decreasing one (3).

\section{Preoxygenation in the ICU with HFNC or standard oxygen: analysis of the available data}

Because an increasing number of patients with acute hypoxemic respiratory failure are treated with HFNC, those that ultimately require intubation will already have 
the device in place to perform preoxygenation.

To date, preoxygenation and apneic oxygenation during the intubation process of critically patients with HFNC was evaluated in one before-after study (9) and four RCTs (10-13) (Table 1). Very similar outcomes (lowest $\mathrm{SpO}_{2}$ and number of $\mathrm{SpO}_{2}$ below $80 \%$ ), similar HFNC settings (50-60 L/min and $100 \% \mathrm{FiO}_{2}$ ) were used in these five studies. Similarly, the comparator was mostly standard bagvalve mask oxygenation in these studies with the exception of one for which the comparator was NIV.

In patients with mild to moderate hypoxemia, the beforeafter study found that use of HFT improved preoxygenation and prevented occurrence of profound desaturation compared to conventional preoxygenation (9). In similar patients, one multicenter RCT found a significant reduction in intubation-related severe adverse events with HFNC but no difference in lowest $\mathrm{SpO}_{2}$ value in comparison with conventional preoxygenation (12) and another a significant increase in $\mathrm{SpO}_{2}$ after preoxygenation with HFNC in those previously receiving low-flow oxygen (11). During the $1 \mathrm{~min}$ of apnea after anesthesia induction, $\mathrm{SpO}_{2}$ dropped significantly in the control group, whereas there was no significant decrease in the HFNC group. In more severely hypoxemic patients, a multicenter RCT reported similar lower $\mathrm{SpO}_{2}$ and number of episodes of profound desaturation between conventional preoxygenation and HFNC (10). The fourth multicenter RCT (13) compared HFT to NIV and will be discussed below.

Taken together, none of these studies found a worse outcome with HFNC and some a significant improvement.

Despite these results, some are still reluctant to use high flow instead of standard oxygen (14).

This may seem intriguing.

No study ever demonstrated a better outcome of ARDS patients ventilated with a Dräger V500 ventilator compared to a Siemens Servo C. Had one the choice however, I am confident no one would hesitate today between the two when choosing a ventilator to manage an ARDS patient.

A significant technological gap separates the two, with better performances and new features in favour of the most recent one.

Isn't the situation similar between standard oxygen and HFNC?

If so, why do would we require HFNC to demonstrate better outcomes?

The same analogy applies to administration of vasopressors in septic shock. Who would nowadays administer vasopressors diluted in a pouch of saline and adjusting the flow with a simple manual flow regulator rather than via a precision syringe pump? Teams readily accepted this technological improvement without requiring a study demonstrating a survival difference between the two devices used in septic shock patients.

\section{Preoxygenation in the ICU with HFNC or standard oxygen: what this new study adds}

Intubation of hypoxemic patients is a hazardous procedure and complications may be fatal (15). Should our concern not be the patients' utmost safety? Most studies have focused on desaturation as primary outcome, because severer hypoxemia is frequent and may lead to cardiac arrest during intubation; however, other complications need also to be addressed.

Recently, Guitton and colleagues compared HFNC to standard bag-valve mask to preoxygenate patients with mild to moderate hypoxemia requiring tracheal intubation (12). The study was a multicentre, open-label, randomized controlled trial. HFNC was set at $60 \mathrm{~L} / \mathrm{min}$ and preoxygenation oxygen flow was $15 \mathrm{~L} / \mathrm{min}$ in the standard group. One hundred and eighty-four patients were enrolled.

The median lowest $\mathrm{SpO}_{2}$ during intubation was not significantly different between the two groups, despite a greater incidence of difficult intubations in the HFNC group.

Similarly, fewer patients in the HFNC group experienced drops in $\mathrm{SpO}_{2}: 12 \%$ vs. $23 \%$ in the standard oxygen group. Overall, a significant higher incidence of severe adverse events was observed in the standard oxygen group compared to the HFNC group. This was also the case for the moderate complications. This was coherent with the results of the multivariate analysis that evidenced an association between HFNC and less episodes of desaturation below 90\% and less intubation-related complications.

Hence, in mild to moderate hypoxemic patients requiring tracheal intubation in the ICU, two independent studies, using different trial designs, come to the same conclusion: HFNC is superior to standard oxygen to prevent intubation-related complications.

\section{Preoxygenation in the ICU: does NIV perform better?}

In patients with more severe hypoxemia, several studies have compared HFNC to non-invasive ventilation (Table 1).

A landmark study by Baillard and colleagues indicated 


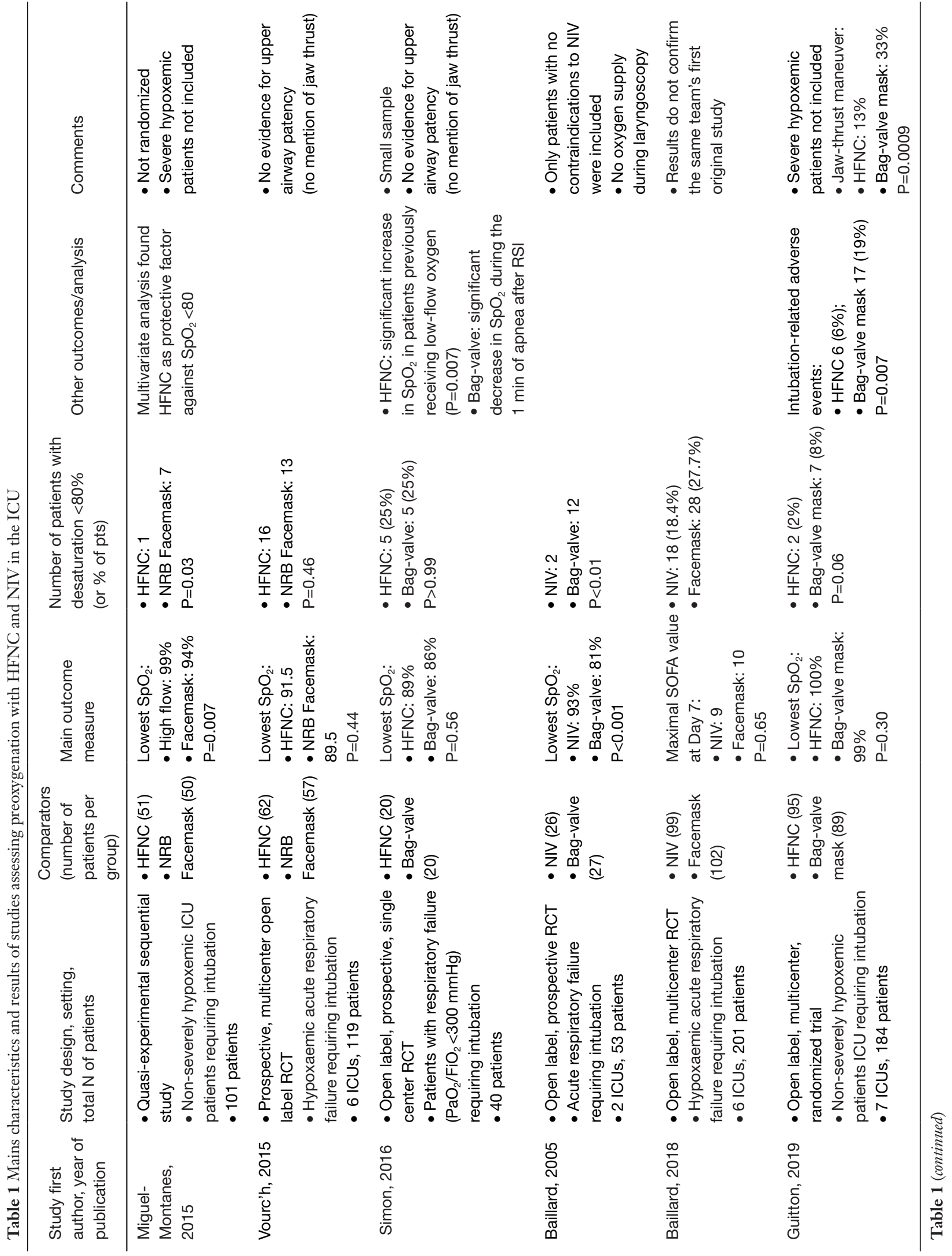




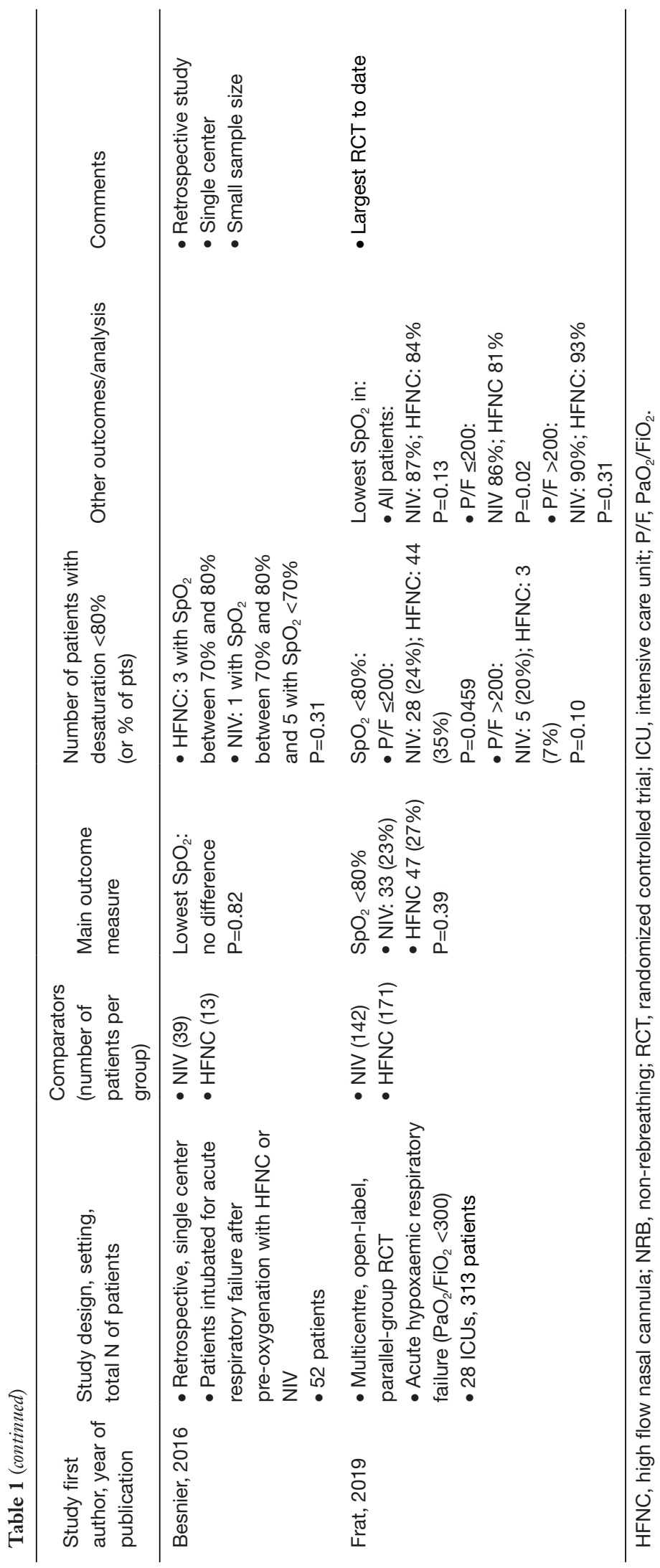




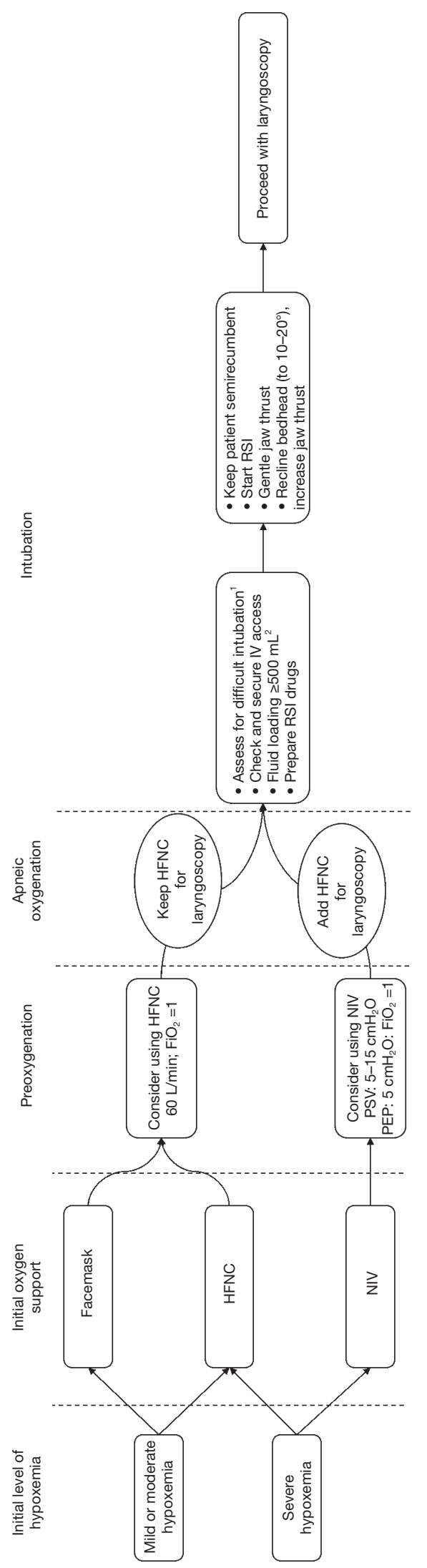

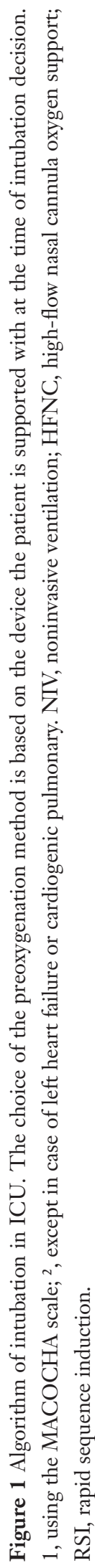

the superiority of NIV over standard oxygen to prevent severe desaturation episodes $\left(\mathrm{SpO}_{2}<80 \%\right)(16)$. However, in a subsequent study, the same authors failed to show any benefits of NIV as a preoxygenation method to reduce organ dysfunction compared with usual preoxygenation in hypoxemic, critically ill patients requiring tracheal intubation (17).

We recently conducted a randomized multicentre control trial that compared NIV to HFNC to ensure preoxygenation of patients with acute hypoxemic respiratory failure requiring tracheal intubation in the ICU (13). If there was no difference in the incidence of severe hypoxaemia ( $23 \%$ with NIV vs. $27 \%$ with HFNC) in the overall study patients, we found that patients with moderate-to-severe hypoxaemia $\left(\mathrm{PaO}_{2} / \mathrm{FiO}_{2} \leq 200 \mathrm{mmHg}\right)$, severe hypoxaemia occurred less frequently after preoxygenation with NIV than with nasal high-flow (24\% vs. $35 \%$ respectively, $\mathrm{P}=0.0459)$. Importantly, serious adverse events did not differ between the two groups.

Hence, although there does seem to exist a benefit in using NIV in the more severe patients, this benefit is small, and is not found for serious adverse events other than desaturation.

\section{Concluding remarks: our patients' safety above all}

Regarding desaturation, it is insightful to look at individual patient data. A quick look at Figure 2 of Guitton and colleagues' study shows that 4 patients in the standard oxygen group experienced desaturation below $50 \%$ (versus none in the HFNC group)! Obviously, figures are much too small for any valid statistical analysis, but in an individual patient safety perspective, these four patients were at great risk for potentially fatal cardiac arrest. Interestingly, similar very profound desaturations were observed by Besnier et al. in patients preoxygenated with NIV but none with HFNC, despite the absence of difference in median lowest $\mathrm{SpO}_{2}$ values between the two devices (18).

Based on these results, we suggest in Figure 1, our practical approach on preoxygenation and apneic oxygenation during intubation of ICU patients.

It is our responsibility as intensivist we take all the necessary precautions so that none of our patients ever experience such desaturations. Data, including the important study by Guitton et al. (12), shows this is be better achieved with HFNC than with conventional preoxygenation. 


\section{Acknowledgments}

None.

\section{Footnote}

Conflicts of Interest: JD Ricard declares travel and accommodation expenses covered by Fisher \& Paykel to attend scientific meetings. J Messika declares travel and accommodation expenses covered by Fisher \& Paykel and CSL Behring to attend scientific meetings. The other authors have no conflicts of interest to declare.

Ethical Statement: The authors are accountable for all aspects of the work in ensuring that questions related to the accuracy or integrity of any part of the work are appropriately investigated and resolved.

\section{References}

1. Ricard JD. Hazards of intubation in the ICU: role of nasal high flow oxygen therapy for preoxygenation and apneic oxygenation to prevent desaturation. Minerva Anestesiol 2016;82:1098-106.

2. Roca O, Messika J, Caralt B, et al. Predicting success of high-flow nasal cannula in pneumonia patients with hypoxemic respiratory failure: The utility of the ROX index. J Crit Care 2016;35:200-5.

3. Roca O, Caralt B, Messika J, et al. An Index Combining Respiratory Rate and Oxygenation to Predict Outcome of Nasal High-Flow Therapy. Am J Respir Crit Care Med 2019;199:1368-76.

4. Frat J-P, Thille AW, Mercat A, et al. High-flow oxygen through nasal cannula in acute hypoxemic respiratory failure. N Engl J Med 2015;372:2185-96.

5. Ni Y-N, Luo J, Yu H, et al. Can High-flow Nasal Cannula Reduce the Rate of Endotracheal Intubation in Adult Patients With Acute Respiratory Failure Compared With Conventional Oxygen Therapy and Noninvasive Positive Pressure Ventilation?: A Systematic Review and Metaanalysis. Chest 2017;151:764-75.

6. Ricard J-D, Gregoretti C. Nasal high-flow preoxygenation for endotracheal intubation in the critically ill patient? Pro. Intensive Care Med 2019;45:529-31.

7. Kang BJ, Koh Y, Lim C-M, et al. Failure of high-flow nasal cannula therapy may delay intubation and increase mortality. Intensive Care Med 2015;41:623-32.

8. Delbove A, Darreau C, Hamel JF, et al. Impact of endotracheal intubation on septic shock outcome: A post hoc analysis of the SEPSISPAM trial. J Crit Care 2015;30:1174-8.

9. Miguel-Montanes R, Hajage D, Messika J, et al. Use of highflow nasal cannula oxygen therapy to prevent desaturation during tracheal intubation of intensive care patients with mildto-moderate hypoxemia. Crit Care Med 2015;43:574-83.

10. Vourc'h M, Asfar P, Volteau C, et al. High-flow nasal cannula oxygen during endotracheal intubation in hypoxemic patients: a randomized controlled clinical trial. Intensive Care Med 2015;41:1538-48.

11. Simon M, Wachs C, Braune S, et al. High-Flow Nasal Cannula Versus Bag-Valve-Mask for Preoxygenation Before Intubation in Subjects With Hypoxemic Respiratory Failure. Respir Care 2016;61:1160-7.

12. Guitton C, Ehrmann S, Volteau C, et al. Nasal high-flow preoxygenation for endotracheal intubation in the critically ill patient: a randomized clinical trial. Intensive Care Med 2019;45:447-58.

13. Frat J-P, Ricard J-D, Quenot J-P, et al. Non-invasive ventilation versus high-flow nasal cannula oxygen therapy with apnoeic oxygenation for preoxygenation before intubation of patients with acute hypoxaemic respiratory failure: a randomised, multicentre, open-label trial. Lancet Respir Med 2019;7:303-12.

14. Hanouz JL, Gérard JL, Fischer MO. Nasal high-flow preoxygenation for endotracheal intubation in the critically ill patient? Con. Intensive Care Med 2019;45:526-8.

15. De Jong A, Rolle A, Molinari N, et al. Cardiac Arrest and Mortality Related to Intubation Procedure in Critically Ill Adult Patients: A Multicenter Cohort Study. Crit Care Med 2018;46:532-9.

16. Baillard C, Fosse JP, Sebbane M, et al. Noninvasive ventilation improves preoxygenation before intubation of hypoxic patients. Am J Respir Crit Care Med 2006;174:171-7.

17. Baillard C, Prat G, Jung B, et al. Effect of preoxygenation using non-invasive ventilation before intubation on subsequent organ failures in hypoxaemic patients: a randomised clinical trial. Br J Anaesth 2018;120:361-7.

18. Besnier E, Guernon K, Bubenheim M, et al. Preoxygenation with high-flow nasal cannula oxygen therapy and non-invasive ventilation for intubation in the intensive care unit. Intensive Care Med 2016;42:1291-2.

Cite this article as: Ricard JD, Gaborieau B, Bernier J, Le Breton C, Messika J. Use of high flow nasal cannula for preoxygenation and apneic oxygenation during intubation. Ann Transl Med 2019;7(Suppl 8):S380. doi: 10.21037/ atm.2019.12.106 